\title{
Colonialidade e gênero no romance Eu, Tituba: bruxa negra de Salem, de Maryse Condé
}

\author{
Alcione Corrêa Alves* \\ Jônata Alisson Ribeiro de Oliveira**
}

\section{Resumo}

Este artigo busca compreender experiências da colonialidade ou, mais precisamente, aquilo que María Lugones (2008) caracteriza como colonialidade de gênero, mediante leitura do romance Eu, Tituba: bruxa negra de Salem, de Maryse Condé (2019). Como recorte necessário ao texto literário, partimos de um exame específico da narradora-protagonista Tituba, em passagens nas quais se observa seus deslocamentos entre fronteiras (físicas e imaginárias) de uma modernidade europeia recém-instalada nas ilhas caribenhas dos anos finais do século XVII e iniciais do século XVIII. Supomos que a mulher negra, uma vez reduzida à animalidade, ao sexo forçado e à escravização, se mostra parte constitutiva de um regime de violência próprio ao sistema colonial moderno de gênero, sendo relevante examinar, a partir das experiências de Tituba no contexto da primeira modernidade, como se constroem de maneira hegemônica o gênero e suas relações. Este trabalho fundamenta-se nas premissas teóricas da noção de colonialidade do gênero, de María Lugones (2005; 2008; 2014).

Palavras-chave: Maryse Condé. Romance. Colonialidade do gênero. Feminismo negro. Literatura Amefricana.

\footnotetext{
* Professor Associado da Universidade Federal do Piauí (UFPI), Doutor em Letras pela Universidade Federal do Rio Grande do Sul (UFRGS), https://orcid.org/0000-0002-8405-430X

** Graduado em Letras - Língua Portuguesa e Literatura brasileira e portuguesa (2013) e mestrado em Letras (2016), ambas titulações obtidas pela Universidade Federal do Piauí. Especialista em Africanidades e Cultura Afro-Brasileira, http://lattes. cnpq.br/2094655241003223.
} 


\title{
Coloniality and gender in Maryse Condé's novel I, Tituba: black witch of Salem
}

\begin{abstract}
This study seeks to understand experiences of coloniality or, more precisely, what María Lugones (2008) characterizes as coloniality of gender upon reading the novel I, Tituba: Black Witch of Salem by Maryse Condé (2019). As a necessary depiction of the literary text, this study starts with a specific examination of the narrator-protagonist Tituba, from passages in which she observes her displacement between (physical and imaginary) borders of a European modernity newly arrived in the Caribbean islands of the late 17th and early 18th century. We assume that the black woman, once reduced to animality, forced sex, and enslavement, proves to be a constitutive part of a regime of violence specific to the colonial/modern gender system. Thus, it would be relevant to examine how gender and its relations are constructed in a hegemonic way from Tituba's experiences in the context of the first modernity. This work is based on the theoretical premises of the notion of coloniality of gender by María Lugones $(2005 ; 2008 ; 2014)$.
\end{abstract}

Keywords: Maryse Condé. Novel. Coloniality of Gender. Black Feminism. Amefrican literature.

Recebido em: 29/09/2021 // Aceito em: 23/12/2021. 
No romance Eu, Tituba: bruxa negra de Salem, retraduzido ao português brasileiro em 2019, sua protagonista, Tituba, nomeando-se desde o título, narra na obra um contexto de experiências vividas da colonialidade na modernidade europeia caribenha, mediante as quais interpretamos, nos limites do presente artigo, as investidas de um projeto moderno de base eurocêntrica que se pretende universal, a partir das estratégias de representação de personagens ingleses no território da ilha de Barbados. Tal escolha, na base da interpretação ora iniciada, reivindica a hipótese ${ }^{1}$ de personagens a construir, em uma diegese, representações de um projeto moderno-colonial europeu (QUIJANO, 2005; BERNARDINHO-COSTA; GROSFOGUEL, 2016). A violação da mulher negra, na figura de Abena, mãe de Tituba, desde as primeiras linhas da narrativa, compõe parte desse empreendimento, nos encaminhando a uma análise sobre o corpo negro feminino violado, dentro do contexto da primeira modernidade. ${ }^{2}$ Abena é reduzida à situação de corpo disponível a um colonizador inglês, enquanto fazia uma travessia forçada da África a Barbados, dentro de um navio negreiro (talvez, paradoxalmente) chamado Christ the King. ${ }^{3}$

Abena, minha mãe, foi violentada por um marinheiro
inglês no convés do Christ the King, num dia de $16^{* *}$,
quando o navio zarpava para Barbados. Dessa agressão
nasci. Desse ato de agressão e desprezo. Quando longas
semanas mais tarde, chegamos ao porto de Bridgetown,

1 E, em um sentido mais amplo, reivindica a hipótese (a ser verificada na forma de um programa amplo de investigação) de ficcionistas amefricanas, contemporâneas, propondo, desde o presente, uma poética habilitada a construir, em diegeses de suas obras, representações de um projeto moderno-colonial. A presente apropriação da categoria Amefricanidade, para compreender as poéticas de escritoras e obras literárias negras nas Américas (lá onde, como termos circulantes em nossa comunidade científica, encontramos, por exemplo, literaturas afroamericanas ou mesmo literaturas negras americanas), parte de nossos esforços recentes em torno das contribuições aportadas por Lélia González (2018), a serem citadas e referenciadas ao longo do presente artigo.

2 De acordo com María Lugones (2014, p. 936), a primeira modernidade, também chamada de modernidade colonial, refere-se ao momento da conquista sobre os países colonizados pelos europeus a partir do século XVI; a segunda modernidade, por sua vez, ainda conforme essa autora, inicia-se a partir da Revolução Industrial, também designada como modernidade capitalista.

3 O termo, traduzido para a língua portuguesa, significa "Cristo, o Rei". 
ninguém notou a condição de minha mãe. (CONDÉ, 2019, p. 17).

Constatação fundamental, a fim deste artigo: como gesto inicial de uma fala sobre si, Tituba se define desde o momento-zero não, de seu nascimento (no que se poderiam incluir as expectativas comumente geradas pelo advento de maternidades não racializadas), mas desde a sua mãe, Abena, e, particularmente, desde o estupro por parte de um marinheiro branco, inglês, a assinalar a violência como momento-zero de vidas de mulheres negras. Para Bell Hooks (2014), a prática do estupro, como parte de uma ordem social sexista colonial, foi um ato de violência usado para doutrinar mulheres negras livres e transformá-las em escravizadas. Assim, Interpretamos que, quando submetida a esse tipo de violação, a princesa axânti, como também era chamada, passa a ser deslocada para o lado mais subalterno das hierarquias dicotômicas, onde, de acordo com María Lugones (2014), a marca do não humano, em dessemelhança com a do humano, é imposta pela perspectiva eurocêntrica a sujeitas(os) colonizadas(os). Isso demonstra o quanto os corpos de mulheres negras, corpas-negras, desde o início da viagem a bordo dos navios, têm estado vulneráveis à violação. Elas, sob tais condições, não tinham poder sobre o próprio corpo e, portanto, não estavam protegidas dos estupros perpetrados pelos colonizadores, contra colonizadas(os), no interior das embarcações.

Nós seguíamos por uma trilha que serpenteava as ervasda-guiné, quando de repente ouvimos um barulho de vozes irritadas. Era Darnell, que destratava um capataz. Ao ver minha mãe, sua expressão mudou radicalmente. Surpresa e alegria brigavam em sua face, e ele exclamou: - É você, Abena? Mas que bom, o marido que eu te dei 
te transformou numa maravilha! Venha cá! [...]

Quando voltei para perto de minha mãe, ela se detinha, ofegante, as costas contra uma cabaceira. Darnell estava parado em pé, a menos de um metro de onde ela estava. A camisa dele estava no chão e a calça estava aberta, revelando a brancura de suas roupas íntimas. A mão esquerda procurava algo bem na altura de seu sexo. Minha mãe berrou, virando a cabeça na minha direção:

- O facão! Me dá o facão!

Eu obedeci tão rápido quanto pude, segurando a enorme lâmina com minhas mãos frágeis. Minha mãe bateu duas vezes. Lentamente, a camisa de linho branco se tornou escarlate.

Enforcaram minha mãe. (CONDÉ, 2019, p. 22-23).

No convés do Christ the King, a violência imputada a Abena assinala o início da narrativa, assim como marca a vida da própria narradora. A violência, como ponto de partida e como variável indispensável à equação de nossas construções identitárias negras, nossos devires-negros (MBEMBE, 2018), demarca as primeiras páginas do romance: o nascimento e a morte de Abena, mãe, seguido do suicídio de Yao, pai, introduzem o presente artigo, com o qual, além de destacar a centralidade de uma retradução dessa obra, para o português brasileiro, em um fluxo de pensamento amefricano traduzido e circulando entre nossa intelectualidade negra, renovando-a, ${ }^{4}$ oferece subsídios ao problema de pesquisa,

4 Ademais da própria retradução do romance de Condé (anteriormente traduzido e lançado, no Brasil, pela Editora Rocco, juntamente com outras obras de Condé, em 1997), desta vez traduzida por Natália Borges Polesso e prefaciada por Conceição Evaristo, tem-se presenciado um contexto mais recente de publicações e traduções de obras centrais a um marco de pensamento amefricano, em que constam tanto traduções como edições organizadas de pensamento amefricano estrangeiro (por exemplo, novas edições em português brasileiro de Patricia Hill Collins, de bell hooks, de Yuderkys Espinosa Miñoso, retraduções de Angela Davis, organização de ensaios de Toni Morrison e de Audre Lorde), assim como novas edições organizando e reunindo ensaios de pensamento amefricano no Brasil como, por exemplo, edições recentes das obras de Beatriz Nascimento, de Lélia González, de Sueli Carneiro. A título introdutório ao artigo e em favor de seu diálogo, de modo mais amplo, com o dossiê do qual faz parte, poder-se-ia propor que a referida circunstância editorial recente, ademais de constituir sintoma de redes intelectuais amefricanas em movimento, também se mostra pensamento a se posicionar, de acordo com Sousa Santos (2007), questionando radicalmente a pressuposição de um pensamento abissal a demarcar a inexistência de pensamento e agência transformadora "do outro lado da linha", do lado em que se circunscrevem nossos Outros. De acordo com o questionamento construído pelo texto-mestre do presente dossiê, este artigo, ao longo de suas análises literárias, visa a uma apresentação de pensamento amefricano contemporâneo compreendido como pensamento em rede, pensamento a circular e promover fluxos a 
a saber: ao nos amparar em uma base teórica decolonial para pensar nossos problemas atinentes a literaturas amefricanas, quiçá os problemas a respeito da relação entre raça e gênero (ou, em termos mais amplos, os problemas atinentes a uma pluralidade de categorias a operar, simultaneamente), em nossas análises à luz da categoria colonialidade, possam receber aportes que dialoguem, ampliando-as, com as possibilidades críticas de uma teoria decolonial a interpretar problemas amefricanos. A partir disso, este artigo visa a construir uma interpretação de $\mathbf{E u}$, Tituba: bruxa negra de Salem, de Maryse Condé, na qual se busca aportar o pensamento de María Lugones, em alguns de seus diálogos possíveis com uma colonialidade concebida desde o pensamento de alguns de seus intelectuais circulantes em nossa comunidade científica - notadamente, desde Aníbal Quijano.

No presente $\operatorname{artigo~}^{5}$ construímos, a partir da premissa teórica da colonialidade do gênero (LUGONES, 2008), uma leitura, de cunho interseccional, sobre as experiências vivenciadas pela narradora-protagonista do romance Eu, Tituba: bruxa negra de Salem, de Maryse Condé (2019). A obra apresenta uma história na qual Tituba narra situações traumáticas, experienciadas por sujeitas(os) negras(os), nos territórios caribenhos e americanos reconstruídos como espaços coloniais de subjugação, quando do advento da dominação das Américas, entre os séculos XVI e XIX, por parte de populações de brancas(os) europeias(eus). Tituba, deslocando-se da ilha de Barbados, de onde é originária, aos Estados Unidos, torna-se vítima, juntamente com dezenas de mulheres brancas, das acusações e condenações atinentes

\footnotetext{
despeito do abismo que lhe é imposto.

5 Este trabalho constitui recorte de uma pesquisa de dissertação de mestrado, defendida no ano de 2016, na Universidade Federal do Piauí (UFPI).
} 
ao famoso processo de caça às bruxas na aldeia de Salem, no estado de Massachussets. O retorno da narradora-protagonista à ilha dá-se por conta de sua participação na rebelião geral, encabeçada por ela e outros negros escravizados, culminando em seu enforcamento, como punição exemplar.

As tramas coloniais, na diegese ${ }^{6}$ do romance, tal como construídas pela voz narrativa de Tituba, permitem observar uma modernidade europeia recém-instalada nas ilhas caribenhas dos anos finais do século XVII e iniciais do século XVIII. Assim, Barbados, antes povoada por indígenas aruaques, tornara-se a "outra face", a sombria e encoberta. ${ }^{7}$ A nova ordem moderna-colonial europeia, trazida pelos colonizadores ingleses para parte do arquipélago por eles colonizada, ${ }^{8}$ a havia transformado em um lugar de dominação e exploração. Navios negreiros desembarcavam massivamente sujeitas(os) negras(os) africanas(os) que, "com os pés acorrentados e uma corda no pescoço", eram levadas(os) a "Bridgetown para encontrar comprador e, em seguida," espalhadas(os) pela ilha, "pais separados de filhos, mães separadas de filhas [...]." (CONDÉ, 2019, p. 25). Desde então, vige na ilha, um modelo eurocêntrico

\footnotetext{
6 O termo "diegese" remete à estrutura narrativa, significando as ações narradas dentro do limite espaço-temporal do próprio texto; refere-se, portanto, à dimensão ficcional, que difere da realidade externa ao texto (GENETTE, 1971).

7 Cabe dissertar que, apesar de Maryse Condé haver nascido guadalupeana, a diegese não se passa em Guadalupe, mas: a) no navio negreiro, com destino a Barbados, local do nascimento de Tituba; b) na ilha de Barbados, onde viveu Tituba, em seus primeiros anos; c) em Salém, nos Estados Unidos; d) e em mais espaços diegéticos que não correspondem a Guadalupe. Será importante assinalar, ao final do presente artigo, que nem todas(os) amefricanas(os) escravizadas(os) nas Américas vêm de uma mesma nação africana, sequer do mesmo porto africano, do que se segue que nem todas(os) amefricanas(os) escravizadas(os) desembarcam nos mesmos portos americanos - muito de nossos processos históricos de escravização poderiam ser mais precisamente compreendidos a partir do estudo das rotas comerciais negreiras, entre os séculos XVI e XIX. É igualmente importante considerar que, quando observamos a ficcionalidade de mulheres amefricanas caribenhas contemporâneas por vezes olvidamos que nem todas as obras devem necessariamente se reportar ao mesmo local de nascimento (biográfico) das escritoras - conclusão que deduzimos geralmente desde um estereótipo (uma imagem de controle, de acordo com COLLINS, 2019; BUENO, 2020) segundo o qual o discurso de sujeitas(os) negras(os) deve necessariamente se reportar a "sua realidade", isto é, aos domínios aos quais circunscrevemos de modo impositivo nossos Outros.

8 Assinalando, de modo brevíssimo: sobre a pluralidade de colonizações do arquipélago que hoje conhecemos como Caribe, assim como sobre a pertinência de tais colonizações tanto com relação a uma definição válida de Caribe quanto a uma chave de leitura de tais obras, consulte-se Gaztambide-Geigel (1996) e Milagros e García (2013).
} 
nunca visto antes por habitantes nativas(os) tampouco pelos novos povos em condição de escravização, que a ocupariam a partir da dispersão forçada. ${ }^{9}$

$\mathrm{O}$ sentido de modernidade presente neste trabalho se relaciona a uma compreensão elaborada por teóricos do pensamento decolonial ${ }^{10}$ latino-americano. Para os intelectuais do grupo Modernidade-Colonialidade, o ano de 1492 constitui o marco do nascimento da modernidade e do "encobrimento" do não europeu, que se inicia pela expansão europeia portuguesa e pelo descobrimento da América Hispânica (DUSSEL, 2005). ${ }^{11}$ A partir desse marco, foram produzidas novas identidades até então desconhecidas nas Américas, ao passo que outras foram redefinidas sob o signo de violências epistêmicas: identidades historicamente novas, como "índios" e "negros", por exemplo - exogenamente nomeados pelos colonizadores, designando, respectivamente, os povos que habitavam os continentes americano e africano - foram hierarquicamente nomeadas, organizadas e consideradas inferiores em relação às populações

9 Ao mesmo tempo que, em Barbados, se impunha um núcleo racional eurocêntrico, autodescrito como o mais desenvolvido e superior em relação a outros povos considerados "atrasados", processo similar, dito civilizatório, acontecia em outros lugares das Américas (inclusive, ou sobretudo, no Brasil), com o domínio por parte de outras populações europeias como, por exemplo, holandeses, franceses, portugueses e, em grande parte do território centro e sul-americano, espanhóis.

10 É importante pontuar as diferenças terminológicas entre os termos "decolonial" e "descolonial". O primeiro, "decolonial", assumido no corpo deste artigo, refere-se à decolonialidade do poder, ou da matriz colonial de poder, a partir de uma teoriapráxis que se situa desde o "sul" - definição não apenas geográfica mas, sobremaneira, política, em muitos aspectos afim a Sousa Santos (2007) - e a um desapego dos acordos da modernidade e do seu imaginário, por vezes, assentado em um simulacro de democracia conforme, por exemplo, Mignolo (2020). Essa decolonialidade acontece quando há o reconhecimento do sujeito de sua colonialidade na modernidade (MALDONADO-TORRES, 2007). O vocábulo "descolonial”, por seu turno, usado com frequência em castelhano e português, refere-se ao gesto de "descolonização", no sentido de desfazer o colonial, aludindo ao fim das administrações coloniais e a uma emancipação dos países antes colonizados. A supressão do "s", proposta por Catherine Walsh, portanto, marca uma distinção: o decolonial, proposto pelo eixo Modernidade-Colonialidade, contrapondo-se à colonialidade, e o descolonial se contrapondo ao colonialismo (SANTOS, 2018).

11 Ao cogitar o ano de 1492, data assinalada como a chegada da delegação espanhola ao arquipélago caribenho, em suas implicações políticas para nossos modos contemporâneos de construir identidades amefricanas, há que se tomar, ademais dos questionamentos decoloniais expostos por Enrique Dussel, a centralidade da pergunta norteadora construída por Sylvia Wynter: "La discusión plantea la siguiente interrogante: ¿cómo debe interpretarse el gran suceso de 1492? ¿Debería percibirse desde la perspectiva de los celebradores, es decir, como un 'hecho glorioso', un 'hecho heroico y audaz' de descubrimiento y exploración, un triunfo para el oeste cristiano que debía liberar a los pueblos indígenas de su Edad de piedra, de su existencia desprovista de la rueda (Hart 19911 ¿o debería percibirse desde la perspectiva de los que disienten, como uno de los 'crimenes monumentales de la historia', como una invasión y conquista brutal que conllevó a un nivel de extinción genocida y a un desastre ecológico aún en curso, sin precedentes en la historia de la humanidad?[...]”(WYNTER, 2017, p. 367-368). 
europeias (QUIJANO, 2005). ${ }^{12} \mathrm{O}$ caráter exógeno dessa nomeação expõe o apagamento de sujeitas(os) racializadas(os) impedidas(os), inclusive, de nomearem a si próprias(os), pois reduzidas(os) unicamente à situação de escravizadas(os). ${ }^{13} \mathrm{O}$ problema exógeno da nomeação constitui, portanto, um gesto de violência contra a existência dessas(es) sujeitas(os), visando a extinguir da história todo um conjunto de existências, toda uma memória coletiva.

Dessa maneira, principiava-se, desde o século XV, "la formación de un orden mundial que culmina, 500 años después, en un poder global que articula todo el planeta." (QUIJANO, 1992, p. 11). A partir desse marco, considerado data de início da operação do Sistema-Mundo moderno-colonial, ${ }^{14}$ primeiramente com o domínio de Portugal e, em seguida, com a colonização hispânica de territórios nas Américas, inicia-se uma concepção do mundo como lugar de uma única história mundial (DUSSEL, 2005). A visão alternativa de modernidade proposta pelo pensamento decolonial nos aponta que o mundo moderno é o

12 Sob tal perspectiva, o presente artigo supõe que as contribuições aportadas por um marco de pensamento decolonial desde Quijano - e, mais adiante, desde Lugones - permitem avanços para compreender a designação de racialização como gesto exógeno de desumanização, mediante violência epistêmica - e do quanto, de um ponto de vista metodológico, se mostra fundamental recorrer a procedimentos habilitados a assinalar a violência existente no centro de tais construções identitárias.

13 Importante, a esse respeito, demarcar a distinção entre os usos de escravizada(o) e escrava(o). O primeiro, opção deste artigo, consiste, como procedimento metodológico caro, em adjetivo delimitando a) uma condição, social, histórica e economicamente circunscrita a um tempo e a um lugar ou, mais propriamente, a um modo de produção econômica vigente em territórios americanos, entre os séculos XVI e XIX e b) uma violência imputada a sujeitas(os) amefricanas(os), em consequência do sequestro e do comércio negreiro, como procedimento metodológico caro(a). O segundo, de uso corrente, consiste em substantivo, circunscrevendo as circunstâncias da escravização, doravante atribuídas como uma essência própria à natureza de populações africanas subsaarianas (de fenótipo negro), de modo a justificar sua desumanização e, por conseguinte, as violências epistêmicas dela decorrentes - dentre as quais se destacam a escravização, assim como seus corolários posteriores, presentes contemporaneamente sob a forma de epistemicídio (CARNEIRO, 2005) e de perpetuação do racismo (ao que se poderia recordar conceitos como, por exemplo, de racismo estrutural).

14 A teoria do sistema-mundo moderno-colonial, como atualização da teoria do sistema-mundo de Immanuell Wallerstein, constitui uma abordagem decolonial que se centra na crítica e na compreensão da reprodução de modelos hegemônicos de hierarquias globais. Assim, o racismo, de acordo com Walter Mignolo (2020), constitui matriz que permeia os domínios do imaginário desse sistema; já o ocidentalismo, ainda nas palavras deste autor, "é a metáfora sobranceira, construída e reconstruída pelas muitas mãos pelas quais passaram a história do capitalismo (Arrighi, 1994) e as ideologias em transformação, motivadas pelos conflitos imperiais [...]." (MIGNOLO, 2020, p.36). O ocidentalismo, portanto, a contrapelo de sua face marginalizada, qual seja, os saberes subjugados, constitui uma espécie de imaginário do sistema-mundo moderno-colonial, que também é chamado por Rámon Grosfoguel (2008, p. 113) de "sistema mundo europeu/euro-norte-americano moderno/capitalista/colonial/ patriarcal $[\ldots] "$. 
resultado das consequências da colonização europeia sobre o globo. Assim:

[...] a Espanha, como primeira nação "moderna" [...], abre a primeira etapa "Moderna": o mercantilismo mundial [...].Para nós, a "centralidade" da Europa Latina na História Mundial é o determinante fundamental da Modernidade. Os demais determinantes vão correndo em torno dele [...] são o resultado de um século e meio de "Modernidade": são efeito, e não ponto de partida. Holanda (que se emancipa da Espanha em 1610), a Inglaterra e a França continuarão pelo caminho já aberto.

A segunda etapa da "Modernidade", a da Revolução Industrial do século XVIII e da Ilustração, aprofundam e ampliam o horizonte cujo início está no século XVI. A Inglaterra substitui a Espanha como potência hegemônica até 1945, e tem o comando da Europa Moderna e da História Mundial (em especial desde o surgimento do Imperialismo, por volta de 1870). (DUSSEL, 2005, p. 29, grifo do autor).

A colonialidade, como lado sombrio da modernidade, constitui ferramenta analítica do pensamento decolonial. A colonialidade do poder, conforme Aníbal Quijano (2005), visa a uma compreensão de como as diversas hierarquias estruturadoras do sistema moderno colonial foram estabelecidas, iniciando-se pela colonização das Américas e expandindo-se para outras partes do mundo, de modo a compreender como as identidades foram produzidas e redefinidas em termos raciais. Embora a perspectiva teórica da colonialidade do poder opere como uma crítica epistemológica da modernidade, por vezes, a variável gênero tem sido, dentro dessa mesma perspectiva, posta à margem de nossos esforços coletivos de compreensão. Eis que o romance de Condé nos impõe tal limite em uma primeira abordagem a partir de Quijano: como compreender o gesto de 
Abena, em defesa da própria integridade, seguido de punição exemplar? Como examinar os recursos narrativos para situar esse gesto? Ante tal constatação, o presente artigo propõe que a raça (ou, mais precisamente: processos de racialização de sujeitas(os) amefricanas(os)) opere como um espaço conceitual à centralidade da classificação da população do mundo no capitalismo global; nesse sentido, a colonialidade do gênero, conforme María Lugones (2008), como uma teoria-práxis do pensamento feminista decolonial latino-americano, manifestase como teoria alternativa para compreender a complexidade da imposição colonial europeia, em termos de gênero e raça. Para Lugones, na colonialidade do gênero, raça e gênero são ficções igualmente poderosas e, por isso, a imposição do sistema de gênero, em seu sentido complexo, tem constituição mútua com a colonialidade do poder.

O que foi dito até agora nos permite abordar a pergunta da interseccionalidade da raça e do gênero dentro do esquema de Quijano. Creio que a lógica dos "eixos estruturais" nos dá algo a mais, mas também algo a menos que a interseccionalidade. A interseccionalidade revela o que não conseguimos ver quando categorias como gênero e raça são conceituadas como separadas uma da outra. A denominação categorial constroi o que nomina. Como feministas de cor, temos feito um esforço conceitual na direção de uma análise que enfatiza a intersecção das categorias raça e gênero, porque as categorias invisibilizam aquelas que são dominadas e vitimizadas sob a rubrica das categorias "mulher" e das categorias raciais "negra", "hispânica", "asiática", "nativo-americana", "chicana", simultaneamente, isto é, as mulheres de cor. [...] Mas para Quijano o sexo parece ser inquestionavelmente biológico. (LUGONES, 2008, p. 81-83, tradução nossa). ${ }^{15}$

15 No original: "Lo dito hasta ahora nos permite abordar la pregunta de la interseccionalidad de la raza y el género dentro del esquema de Quijano. Creo que la lógica de "ejes estructurales" hace algo más pero também algo menos que la interseccionalidad. La interseccionalidad revela lo que no se ve cuando categorías como género y raza se conceptualizam 
$\mathrm{Na}$ colonialidade do poder, há interconectividade entre as instituições controladoras do trabalho, da família burguesa, da autoridade e da intersubjetividade. Porém, nesse modelo, dado de forma incompleta, o gênero se circunscreveria a uma explicação pautada na diferença biológica do sexo, sem exame do seu conceito, tampouco de como mulheres negras e indígenas têm sido destituídas de poder. Essas são algumas das lacunas assinaladas por Lugones na teorização de Quijano sobre a colonialidade do poder, haja vista um limite da categoria "eixos estruturais", insuficiente ante formulações contemporâneas de interseccionalidade. Para Cláudia Pons Cardoso (2012), a colonialidade é apenas uma dentre as várias abordagens de resiliência do colonialismo, visando a compreender historicamente as lógicas de dominação do mundo moderno: por exemplo, a compreensão de como identidades modernas - europeu, asiático, africano, latino - têm sido construções racializadas. Cardoso (2012, p. 95) afirma que Quijano "não está imune aos efeitos da própria colonialidade no que se refere ao viés androcêntrico e heteronormativo [...]", quando este parece admitir que o corpo sexuado é binário, reproduzindo um pensamento moderno, o de reconhecer somente construções identitárias baseadas no feminino e no masculino. Em tal movimento, Cardoso se ampara em Lugones, ao constatar uma limitação da abordagem de gênero no modelo proposto por Quijano, dado que raça não pode ser um conceito totalizante, de modo a ocultar o gênero como categoria histórica.

No convés do Christ the King, Abena não tinha a seu

como separadas unas de otras. La denominación categorial construye lo que nomina. Las feministas de cor nos hemos movido conceptualmente hacia un análisis que enfatiza la intersección de las categorías raza y género porque las categorías invisibilizan a quienes somos dominadas y victimizadas bajo la categoría "mujer” y bajo las categorías raciais 'Black', 'hispanic', 'Asian', 'Native American', 'Chicana' a la vez, es decir a las mujeres de color [...] Pero para Quijano, el sexo parece ser incuestionablemente biológico.” (LUGONES, 2008, p. 81-83). 
alcance recursos para se proteger. Mulheres negras, nas palavras de Bell Hooks (2014, p. 15-16), por serem menos resistentes em força do que homens negros, "eram alvo acabado para qualquer homem branco que podiam escolher o abuso físico e torturá-las [...]". Essa prática não ficou restrita aos espaços dos navios, permanecendo em outros espaços depois da travessia, no calabouço, na casa-grande, na lavoura. Nesse último espaço, dentro de uma plantação da ilha, Abena torna-se vítima de um segundo assalto sexual praticado por outro colonizador inglês e, dessa vez, como resposta ao ato de violência, ela o fere, munida de um facão, culminando em sua criminalização por desobediência (ao tentar impedir o próprio estupro) e em condenação à morte no patíbulo.

Enforcaram minha mãe.

Vi Seu corpo girar nos galhos baixos de uma mafumeira. Ela havia cometido um crime sem perdão. Tinha golpeado um branco. Ainda que não o tivesse matado. Em sua fúria desajeitada, apenas conseguiu cortar seu ombro.

Enforcaram minha mãe.

Todos os escravos foram convidados para sua execução. Quando, de nuca quebrada, ela entregou sua alma, um canto de revolta e de ira se ergueu sobre todos os peitos que os capatazes fizeram calar com grandes golpes de chicote. Eu, refugiada na saia de uma mulher, senti endurecer em mim, como lava, um sentimento que não me abandonaria nunca mais, um misto de terror e luto.

Enforcaram minha mãe.

Quando seu corpo girou no vazio, apenas tive forças para me afastar com passos pequenos, agachar e vomitar sem parar sobre a relva. (CONDÉ, 2019, p. 23).

O sentido da anáfora "enforcaram minha mãe", presente no discurso de Tituba, simboliza a destituição deliberada de vozes e vontades negras, do despojamento de suas memórias. 
Trata-se da minimização intencionada de histórias negras e do "enforcamento" de suas subjetividades na modernidade. Logo, o corpo negro colonizado, girando pendurado "no vazio", pertencia a uma mulher negra, livre em sua aldeia natal, Akawapim, e que, posteriormente, ao ser capturado e transformado em corpo escravizado, nas Américas, viu perdidas suas autonomia e subjetividade. A anáfora "enforcaram minha mãe" significa, atualizando, o corpo de Abena (trazia, dessa forma, um nome, uma identidade), princesa dos axânti (possuía, inclusive, uma história), esposa de Yao (também axânti) e mãe biológica de Tituba. Os primeiros anos da infância de Tituba foram marcados por múltiplas violências desse tipo, perpetradas contra seus familiares, resultando em irreparáveis perdas. O suicídio de Yao, a morte de sua mentora Man Yaya e, principalmente, a pena capital de Abena impactarão de forma traumática o restante de sua existência (um fim semelhante ao da mãe também lhe aguardará ao final do romance).

\begin{abstract}
Enforcaram minha mãe.
Todos os escravos foram convidados para sua execução. Quando, de nuca quebrada, ela entregou sua alma, um canto de revolta e de ira se ergueu sobre todos os peitos que os capatazes fizeram calar com grandes golpes de chicote. Eu, refugiada na saia de uma mulher, senti endurecer em mim, como lava, um sentimento que não me abandonaria nunca mais, um misto de terror e luto.
\end{abstract}

Enforcaram minha mãe. (CONDÉ, 2019, p. 23).

Esse violento confinamento colocará Tituba ante a (im) possibilidade de exercer a maternidade: ser mãe poderia adquirir todos aqueles sentidos bonitos e nobres para ela se crianças negras fossem efetiva e humanamente crianças, em vez de mão de obra, se elas fossem sujeitas "iluminada[s] 
pelo sol das brincadeiras, das caminhadas, das andanças [...]" (CONDÉ, 2019, p. 81), em vez de objeto. Nesse momento, Tituba se insurge dissimuladamente, desde aquele local em que se é mais atingido pelo opressor: o corpo negro feminino, historicamente sexualizado, racializado e interditado à razão; recebe importância, dentro do romance, o lugar do aborto e do infanticídio na luta das mulheres negras escravizadas por sua liberdade, uma luta na qual a posse do próprio corpo e a decisão pela vida de seus próprios filhos as colocam em protagonismo. Desse modo, o aborto e o infanticídio adquirirão significações políticas na modernidade quando Tituba decide não gerar.

De acordo com Quijano (2005), existiu um dualismo radical imposto pela visão eurocêntrica, redundando no mito da objetificação do corpo como natureza: tal mito, foi um dos responsáveis por racializar e, consequentemente, inferiorizar os povos, justificando sua dominação. Ao considerar corpo e alma como entidades distintas, a racionalidade eurocêntrica do pensamento socializou que o primeiro não pode ser outra coisa além de objeto de conhecimento associado à natureza; a alma, por sua vez, constituía o lugar da razão e, "desse ponto de vista o ser humano é, por excelência, um ser dotado de 'razão', e esse dom se concebe como localizado exclusivamente na alma. Assim, o corpo, sem capacidade de raciocinar, não possui elo com a razão, atrelada ao sujeito [...]" (QUIJANO, 2005, p. 118) ${ }^{16}$ A partir desse pensamento, determinadas raças não podem, em hipótese alguma, serem sujeitos racionais, pois são considerados objetos cujos corpos estão mais próximos da natureza do que os brancos e, dessa maneira, convertidos em domináveis e exploráveis.

16 Tal ideia dialoga com o princípio de uma metafísica da presença, proposta por Jacques Derrida em L'écriture et la différence; e desdobrada por Jonathan Culler, em On deconstruction (ambos textos já contando com traduções em português brasileiro). 
Nesses termos, Tituba e Abena, caracterizando a realidade opressiva das sujeitas racializadas, foram fixadas no lado mais violentado e desumanizado de uma dicotomia hierárquica, concebida pelo sistema moderno colonial de gênero. Nesse lado do sistema, elas foram convertidas em objetos sexuais e tiveram suas fisionomias associadas ao grotesco e ao sexual: "é certo que a cor da pele de vocês é sinal da sua danação [...]" (CONDÉ, 2019, p. 59). A dicotomia hierárquica, para Lugones (2014), constituía um importante componente dos processos de imposições culturais, históricas e ideológicas responsáveis por formatar um novo universo, intersubjetivo, de dominação dos europeus sobre outros povos do mundo, como indígenas das Américas e africanas(os), categorizando-as(os) como animais, seres sem razão, selvagens, estúpidas(os), promíscuas(os), deformações do macho ou aberrações da perfeição masculina. Operada pela máquina colonial, a dicotomia hierárquica surge nesse cenário como uma ferramenta normativa de controle, classificando povos colonizados em uma categoria de não humanidade porque não pertenciam à raça europeia, branca. A construção do cenário de violência contra mulheres negras escravizadas compunha parte de uma ordem que buscava garantir o funcionamento da máquina colonial europeia, do seu sistema moderno colonial de gênero; por isso, era necessário que sujeitas(os) negras(os) colonizadas(os) se configurassem em peça principal nessa manutenção.

Por seu turno, o outro lado da dicotomia hierárquica se autodefine como a face do humano e do civilizado, acentuando a distinção dicotômica entre homens e mulheres brancas europeias. As(os) personagens brancas(os) do romance de Maryse Condé, como Samuel Parris, Elizabeth Parris, Darnell Davis, Jennifer 
Davis e Susanna Endicott, são representativas(os) daquilo que o perfil eurocêntrico impôs dentro dos próprios limites conceituais de raça e gênero. Samuel Parris, como sujeito heterossexual, cristão e civilizado, reproduz a imagem do homem branco, ao passo que Elizabeth Parris representa, na diegese da obra, o modelo de mulher ideal, obediente e subordinada a uma doutrina moralizadora do corpo e do sexo, entendida, nos termos de Lugones (2014, p. 936), "como alguém que reproduzia raça e capital por meio de sua pureza sexual, sua passividade, e por estar atada ao lar a serviço do homem branco europeu burguês [...]". Suas confissões dos pecados do dia para o marido, durante as orações noturnas, demonstravam uma preocupação exagerada com o zelo mental, já a obsessão com a pureza física fazia com que assuntos relacionados ao corpo, como o sexo, fossem rigidamente censurados. O sexo, considerado por Elizabeth Parris um ato odioso e "herança de Satanás em nós" (CONDÉ, 2019, p. 61), servia apenas para aliviar as incontinências do marido.

É importante salientar que, de acordo com Hooks (2014), o símbolo da pureza e do não sexual atribuído à mulher branca foi-se propagando no decorrer dos tempos, tornando-se essa sólida representação a partir do século XIX. De pecadoras e sedutoras sexuais, culpadas pelo pecado original, passaram a ser exaltadas pelos homens como deusas, dignas de amor, admiração e respeito. Porém, à medida que a sexualidade da sujeita branca foi suprimida e associada ao símbolo da virgem Maria, mãe, companheira e subserviente, a sujeita negra passa a ser explorada no submundo massivo da prostituição e culpada por levar "os homens brancos para longe de sua pureza espiritual [...]". (Hooks, 2014, p. 26). Partindo desses pressupostos, no 
romance, essa dicotomia hierárquica pode ser construída do seguinte modo: de um lado, Elizabeth Parris traduz o padrão de identidade moralista imposto pelo sistema moderno colonial de gênero, representada por meio de signos positivos de identidade; em contrapartida, dentro desse mesmo sistema, às sujeitas negras, como Tituba e Abena, são impostos os estereótipos de pagãs sexuais e de personificação da maldade.

A diferença racial passa a ser gerada e organizada desde aquilo que Lugones (2008) chamou de "lado claro/visível" do sistema moderno colonial de gênero. Nesse lado, o sexo, como estrutura binária e sociologicamente construídos em termos biológicos, reporta diretamente a homens e mulheres brancas burguesas, tornando sua significação ainda mais hegemônica dentro de um sentido colonial moderno; além disso, elementos como patriarcalismo e heteronormativismo tornam-se importantes para o gerenciamento da ordem colonial. Assim, ao tomar aspecto durante as expedições coloniais e se consolidar na modernidade tardia, o lado claro/visível do sistema de gênero heterossexista, patriarcalista legitimou o lugar dos homens brancos e burgueses no topo da hierarquia social, determinando o julgamento do macho colonizado não humano a partir do entendimento do que seria o "homem" branco; também produziu estereótipos e histórias únicas, próprias às mulheres brancas burguesas, excluindo-as da esfera pública, da autoridade coletiva e da produção do conhecimento; à fềmea colonizada não humana, por sua vez, foi outorgado o entendimento normativo da "mulher" (LUGONES, 2014; 2008).

Dentrodessadiscussão, elucidamosqueainterseccionalidade constitui um ponto chave para a construção da teoria-práxis da colonialidade do gênero. A interseccionalidade, como marco 
analítico do feminismo negro, auxilia na compreensão dos motivos que levaram as mulheres negras à subalternização no mundo dominante do patriarcado. Embora os efeitos do racismo ainda atuem com bastante impacto no status social das mulheres negras, a intersecção indica que outras práticas discriminatórias são aduzidas a seu histórico cotidiano. Para Patrícia Hill Collins (2012), a raça não é indicadora exclusiva de diferença grupal, porque as histórias particulares das mulheres negras, dentro de uma matriz única de dominação, são caracterizadas por múltiplas opressões. Em outras palavras, classe, gênero e sexualidade também são atuantes nessa diferença. A dinâmica do trato diferencial, relacionada à interseccionalidade, pode ser examinada desde a obra de Condé ou desde uma literatura de mulheres amefricanas que resgata e representa a ação, a experiência e o conhecimento não valorizado da figura da mulher negra do passado. O espaço literário, então, se torna uma ferramenta imprescindível de resistência a opressões, operando de modo interseccional: essa ideia de sujeitas percebidas na intersecção consta, no romance, por exemplo, em seu momentozero, a partir do estupro de Abena, e em Tituba, percebida como protagonista em-intersecção. Isso diz muito sobre nossa análise na obra, assim como sobre nossa sempre necessária vigilância epistemológica e cuidado metodológico indispensável à interpretação de textualidades negras: sujeitas(os) negras(os), antes de intersecções, somos gente.

Tomando como base as afirmações de Jurema Werneck (2010), as mulheres negras, como agentes identitárias e políticas, são resultados do enfrentamento das agressões físicas e das identidades negativas a elas atribuídas, por meio da dominação ocidental eurocêntrica. Tituba não era atravessada por apenas 
uma, mas por diferentes formas de opressões interconectadas e, por isso, suas experiências de mulher fogem aos padrões estabelecidos pelo patriarcado europeu ao homem negro, afinal "brancos ou negros, a vida é boa demais para os homens [...]" (CONDÉ, 2019, p. 136), assim como para a mulher branca - ao se cogitar a trajetória de Tituba na diegese, quando comparada à de Elizabeth Parris ou à de Susanna Endicott. Tituba, tomando consciência da situação subalterna da mulher negra, afirma não pertencer ao mesmo mundo de mulheres brancas como Betsey e da senhora Parris: apesar de toda afeição e solidariedade que sentia por elas, nada podia mudar sua condição de mulher negra. Destacamos que Susanna Endicott, por seu turno, viúva de um rico plantador, significa, na obra, uma parcela branca feminina permeada de privilégios, com acesso a recursos e alguns poderes. Para tanto, em consonância com Yen Le Espiritu (apud LUGONES, 2005, p. 67), ressaltamos "que algunas mujeres ostentan un poder cultural y económico sobre ciertos grupos de hombres [...]". No romance, embora houvesse libertado, após a morte de seu marido, os sujeitos negros que viviam em situação de escravização, Endicott manteve apenas o jovem negro John Índio constituindo para protagonista um paradoxo incompreensível que poderia ser explicado pelo fato de que Endicott era francamente contrária à escravatura, ainda que detestasse aqueles sujeitados a ela.

Desde quando submetidas à escravização, esse caráter interseccional das opressões de raça e gênero já era percebido por várias intelectuais negras femininas das Américas, como a de Sojouner Truth, que questionavam a dominação masculina e a postura racista da mulher branca. Truth, ${ }^{17}$ como sujeita identitária

17 Nascida no Condado de Ulster, em Nova York, em 1797, e foi emancipada em 1787. Sojouner Truth foi pregadora pentecostal, abolicionista e defensora dos direitos das mulheres. 
e política, assinala o intenso desejo de libertação dos sistemas opressores da mulher negra, nos Estados Unidos do século XIX:

Muito bem crianças, onde há muita algazarra alguma coisa está fora da ordem. Eu acho que com essa mistura de negros (negroes) do Sul e mulheres do Norte, todo mundo falando sobre direitos, o homem branco vai entrar na linha rapidinho. Aqueles homens ali dizem que as mulheres precisam de ajuda para subirem em carruagens, e devem ser carregadas para atravessar valas, e merecem o melhor lugar onde quer que estejam. Ninguém jamais me ajudou a subir em carruagens, ou a saltar sobre poças de lama, e nunca me ofereceram melhor lugar algum. E não sou uma mulher? Olhem para mim? Olhem para meus braços! Eu arei e plantei, e juntei a colheita nos celeiros, e homem algum poderia estar à minha frente. E não sou uma mulher? Eu poderia trabalhar tanto e comer tanto quanto qualquer homem desde que eu tivesse oportunidade para isso - e suportar o açoite também! E não sou uma mulher? Eu pari treze filhos e vi a maioria deles ser vendida para a escravidão, e quando eu clamei com minha dor de mãe, ninguém a não ser Jesus me ouviu! E não sou uma mulher? ${ }^{18}$

O excerto citado é parte de um conhecido discurso de Sojouner Truth, intitulado "And ain't I a woman?", traduzido como "E não sou eu uma mulher?", proferido na Convenção dos Direitos das Mulheres há mais de um século, nos Estados Unidos. De acordo com Donna Haraway (1993, p. 283), Truth evoca “os temas do servo sofredor para reivindicar os status de humanidade para a figura chocantemente imprópria/inapropriada da situação feminina negra no Novo Mundo, portadora da promessa da humanidade também para os homens [...]". Em um contexto de injustiça social, em que Truth foi escravizada, estuprada pelo feitor e testemunha da venda de alguns dos seus filhos,

18 Tradução de Osmundo Pinho. Disponível em: < https://www.geledes.org.br/e-nao-sou-uma-mulher-sojourner-truth/>. Acesso em: 25 mar 2020. Em 2019 foi publicada uma edição bilíngue (inglês e tradução brasileira) do ensaio de Truth, pela Editora Figura de Linguagem (TRUTH, 2019). 
seu discurso consiste em uma resposta às ideias de um sistema colonial racializado que, à época, justificou a subjugação da mulher negra. Corroborando Patrícia Hill Collins (2012, p. 105), interpretamos que o discurso de Truth participa de um corpo coletivo de saberes a desafiar pontos de vistas hegemônicos, como aquelas proposições de que os grupos subordinados são menos "pessoas" que seus opressores e, por isso, são "menos capaces de interpretar sus proprias experiências [...]". Ao tecer reflexões sobre o significado de ser "mulher", Truth prova que a consciência política de sua situação subalterna não era defeituosa, como seus opressores queriam e imaginavam. Embora exercesse atividades historicamente designadas aos homens, como arar, plantar e juntar a colheita nos celeiros, sua condição de mulher, ainda que fosse diferente em termos de raça e classe, não diferia daquela de outras mulheres brancas da classe média e escolarizada de seu país e, portanto, sua reivindicação por justiça social não era menos legítima. ${ }^{19}$

Como se pode constatar, considerações como as de Truth têm provocado novas interpretações sociais de dominação e resistência, evidenciando "novas formas de saber que permitem/ têm permitido aos grupos subordinados se autodefinirem a partir de suas próprias realidades." (CARDOSO, 2012, p. 58). Cabe enfatizar que não só o pensamento de Truth, mas de outras mulheres negras de séculos passados, como Harriet Tubmon (1820?-1913), Ida B. Wells (1862-1931) e Mary Church Terrell

19 A significação hegemônica de "mulher" aliada às noções de "experiência" e "política pessoal", segundo Luiza Bairros (1995), foram tomadas, em um determinado contexto, como conceitos básicos para a formação de uma organização política independente conforme os interesses de uma coletividade composta por mulheres brancas heterossexuais de classe média. No discurso clássico feminista, a priorização da categoria hegemônica do termo "mulher" impediu o reconhecimento das experiências vividas pelas mulheres negras e, como tal, não deu conta da diferença que a consequência da opressão sofrida teve em suas identidades (CARNEIRO, 2011); isso porque a luta contra a opressão sexista, inicialmente tida como principal pauta do movimento feminista nas décadas de 1960 e 1970, foi uma reivindicação executada isoladamente, sem a participação das principais vítimas dessa opressão. Assegura-se, portanto, que as verdadeiras prejudicadas, como aponta hooks (2014), eram uma maioria com pouco ou nenhum grau de instrução, duplamente subjugadas por serem, além de mulheres, pobres e não brancas. 
(1863-1954), bem como o resgate de repertórios de mitos sagrados de figuras femininas de alguns povos da África, ${ }^{20}$ serviram como bases à formação de um pensamento feminista negro que começou a ganhar espaço a partir da década de 1980; nesse período, diversas mulheres negras, desejando recuperar e testemunhar suas próprias histórias de apropriações, vivências e sobrevivências, deram continuidade aos questionamentos de determinadas proposições universalistas, reforçadas pelo patriarcado e por um quadro clássico feminista que desconsiderava a interseccionalidade das categorias de opressões (BAIRROS, 1995).

Isso posto, tomando a interseccionalidade como ponto de partida para a construção da teoria da colonialidade do gênero, Lugones (2008) afirma que na modernidade eurocentrada e capitalista, a homogeneização da raça e do gênero subalterniza aquelas(es) socialmente classificadas(os) abaixo de grupos tidos como hegemônicos, tornando o processo binário, dicotômico e hierárquico. Com isso, a categoria "mulher" legitima as mulheres brancas, de classe média e heterossexuais, e a categoria "homem" legitima homens brancos, burgueses e heterossexuais. Destacase que homens negros também constituem um grupo hegemônico que, na hierarquia social, estão acima das mulheres negras e que, portanto, a categoria "negro" legitima homens negros e heterossexuais. A consequência desse processo de separação e

20 Conforme Jurema Werneck (2010, p. 12), Nanã, Iemanjá, Iansã, Oxum e Obá são apenas algumas das divindades da tradição ioruba que, a partir da década de 1970, retornaram como "força organizativa das diferentes facções do movimento antirracista e, principalmente, o antirracismo feminista das mulheres negras e suas organizações [...]". Segundo a autora, tais mitos foram transportados por mulheres Africanas em circunstâncias adversas durante o período das travessias transatlânticas e que, em pleno século XXI, ainda é preservado na tradição afro-brasileira. Assim como os iorubas, os povos bantus e suas divindades femininas também difundiram "modelos de mulheres fortes, guerreiras, sensuais, muitas delas com os mesmos nomes e atributos das divindades iorubas. Entre as diferenças, destacam-se as novas modalidades de articulação cultural que estabeleceu a partir de intercâmbios com outras culturas marginalizadas, e com as mulheres destas culturas, nas periferias urbanas do país e das áreas rurais. Assim, ao lado das diferentes divindades de origem africana, cultuam também divindades de origem indígenas, entre elas as índias guerreiras (chamadas caboclas - a uma delas devo meu nome, Jurema), as ciganas, as prostitutas, as que vivem nas ruas." (WERNECK, 2010, p. 12). 
homogeneização de categorias que seleciona e socializa modelos hegemônicos é a invisibilização de sujeitas(os) percebidas(os) apenas do outro lado do sistema colonial-moderno de gênero, o "lado oculto/escuro". Operando em conjunto com seu oposto, ele atua com mais força na vida de quem só existe (e só pode ser percebida(o)) na intersecção - como, por exemplo, mulheres negras, mulheres indígenas e sujeitas(os) do terceiro gênero.

A intersecção nos mostra um vazio. Por isso, uma vez que a interseccionalidade nos mostra o que se perde, ficamos com a tarefa de reconceitualizar a lógica da intersecção, para, desse modo, evitar a separação das categorias existentes e o pensamento categorial. Somente ao perceber gênero e raça como tramados ou fundidos indissoluvelmente, podemos realmente ver as mulheres de cor. Isso significa que o termo "mulher", em si, sem especificação dessa fusão, não tem sentido ou tem um sentido racista, já que a lógica categorial historicamente seleciona somente o grupo dominante - as mulheres burguesas brancas heterossexuais - e, portanto, esconde a brutalização, o abuso, a desumanização que a colonialidade de gênero implica. (LUGONES, 2008, p. 82, tradução nossa). ${ }^{21}$

À vista disso, ao reconstituir a história de Tituba, Condé também constrói, para citar os termos de Alcione Alves (2015), uma narrativa de si que se nega a fazer parte da dimensão do invisível, daquilo que não existe, reafirmando a constância de falas do passado que sempre estiveram se expressando e, destarte, existindo. Tituba, narrando sua própria história, questiona, desde um lugar próprio e situado, hierarquias (europeias) impostas aos

21 No original: "La intersección nos muestra un vacío. Por eso, una vez que la interseccionalidad nos muestra lo que se pierde, nos queda por delante la tarea de reconceptualizar la lógica de la intersección para, de ese modo, evitar la separabilidad de las categorias dadas y el pensamento categorial. Solo al percibir género y raza como entretramados o fusionados indisolublemente, podemos realmente ver a las mujeres de color. Esto implica que el término «mujer» en sí, sin especificación de la fusión no tiene un sentido o tiene sentido racista, ya que la lógica categorial historicamente há seleccionado solamente el grupo dominante, las mujeres burguesas blancas heterosexuales y por lo tanto ha escondido la brutalización, el abuso, la deshumanización que la colonialidad del género implica." 
povos das Américas e da África que, vítimas desse processo de racialização e sexualização, têm sido deslocados ao polo mais violento, reduzidos à animalidade, à "agente visível de Satanás", à condição de escravização por homens e mulheres brancas. Segundo Luiza Bairros (1995, p. 461), não existe identidade única para mulheres, pois "a experiência de ser mulher se dá de forma social e historicamente determinados [...]". Tituba expressa uma visão dessas diferenças, com base em suas experiências e nas de personagens que representaram, para ela, padrões femininos negros: sua mãe, Abena, e sua mentora, Man Yaya. Temos, nesse sentido, distintas sujeitas negras, históricas e políticas. As situações de opressões nas quais a mãe foi vítima, ao ter sido escravizada, estuprada por um homem branco inglês e punida na forca por recusa a um novo estupro sob condições análogas, expôs Tituba a uma sorte ainda mais angustiante, quando comparada às violências imputadas, na diegese, a homens negros e mulheres brancas.

O lado oculto/escuro do sistema, caracterizado por um regime de violência, redundou na redução da mulher indígena e da mulher negra escravizada à animalidade, sob a condição de corpo disponível, como percebidos mediante experiências, reiteradas, de Tituba e Abena. Se, no lado claro/visível do gênero, a religião puritana considerou a sexualidade feminina como maligna e ser mulher, no significado hegemônico do termo, uma maldição, ${ }^{22}$ no lado oculto/escuro há uma desvalorização dupla

22 "Tituba, você não acha que ser mulher é uma maldição?" (CONDÉ, 2019, p. 62). No primeiro parágrafo de seu prefácio à retradução da obra de Condé (texto-base ao presente artigo), Conceição Evaristo assinala o caráter intransigente da concepção religiosa em jogo em Salem, praticada por estadunidenses e descendentes ingleses na cidade, ao longo da diegese: "Ali [em Salem], várias pessoas, que viviam sob a influência de uma doutrina cristã intransigente, puritana e supersticiosa, ao serem apontadas como bruxas, foram condenadas à morte. Entre as pessoas havia uma mulher negra escravizada, originária de Barbados, conhecida como Tituba. Sobre ela caía a suspeita de professar e praticar hoodoo. A suspeição foi construída a partir de comportamentos estranhos de crianças das quais Tituba cuidava, em sua função de 'mãe preta' - lugar também bastante conhecido na história da escravização e de subalternização das mulheres africanas e de suas descendentes em solo brasileiro, e quem sabe em todas as Américas [...]" (CONDÉ, 2019, p. 5). Ademais de salientar a religiosidade trazida pela colonização inglesa como, ela também, uma variável na equação de uma análise interseccional das violências imputadas a 
da figura da mulher negra, com base em imagens não só sexistas mas, também, racistas, operando em sua vida de forma múltipla, contínua e sistemática. Tituba, como mulher, negra e colonizada, era considerada, pela comunidade de homens e mulheres puritanas da aldeia de Salem, uma bruxa e, portanto, agente visível e direto de Satanás, incapaz de fazer o bem. Cumpre salientar que a visão da narradora-protagonista acerca do ofício de bruxa fora significada em relação à visão estereotipada dos puritanos de Salem: se, na definição de habitantes da cidade, o termo dizia respeito a isso que eles temiam, ser uma feiticeira significava, portanto, um ser que curava e deveria ser tratada com respeito. Tal entendimento era impossível de ser alcançado pela população branca, de origem inglesa, colonizadora tanto da ilha de Barbados quanto da Nova Inglaterra, nos Estados Unidos dos séculos XVII e XVIII. A perspectiva da feiticeira como figura que mantinha "parte com Satanás" (CONDÉ, 2019, p. 41) já era uma sólida realidade imposta pela religião cristã, na Europa desde o século XV, atravessando gerações, até o século XVIII. O processo de caça às bruxas, tanto por parte dos protestantes quanto da Inquisição, como efeito da colonização e da colonialidade do gênero, se estende, conjuntamente, da Europa para a América e África (MENDOZA, 2014).

Dentro do sistema moderno-colonial de gênero, tanto a discriminação de gênero institucionalizada pelo patriarcado quanto o imperialismo racial tornaram-se parte essencial de uma ordem social e política trazida pela colonização europeia, o que tem se refletido na condição social de mulheres negras escravizadas nas Américas, especificamente no contexto de

\footnotetext{
Tituba e a sujeitas(os) racializadas(os) na diegese do romance de Condé, a citação de Evaristo alude a um elemento apropriado a fundamentar abordagens comparativas entre ficcionalidades de mulheres amefricanas, a saber, a função de "mãe preta" sobre a imagem de controle em torno das mammies, ver Collins (2019); sobre o elemento propriamente metodológico a amparar análises de ficcionalidades amefricanas, destaca que se a analise da figura de Nanny, conforme González (2018).
} 
caça às bruxas. Essas duas forças opressoras são responsáveis por deslocar Tituba para o centro das acusações advindas inicialmente de crianças e adolescentes que se diziam por ela enfeitiçadas durante o incidente que se desdobrou em Salem; ${ }^{23}$ as lentes do sexismo e do racismo, desde a perspectiva dos habitantes de Salem, percebiam, em Tituba, uma figura estrangeira personificada por Lúcifer, culpabilizando-a pelos males que se abatiam sobre a aldeia: "Você, fazer o bem? Você é uma negra, Tituba! Você só pode fazer o mal! Você é mal!" (CONDÉ, 2019, p. 101). Como sujeita em-intersecção, Tituba se apresenta, dentro do episódio histórico de caça às bruxas, do lado oculto/escuro do sistema de gênero; seu processo de acusação e condenação, dentro do sistema moderno-colonial do gênero implantado nas Américas, é justificado com base no sexismo, razão pela qual diversas mulheres brancas foram levadas à prisão e à forca durante o incidente e, também, com base no elemento racial, pois a experiência histórica da protagonista, ao longo da diegese, estava ligada a sua ancestralidade negra. A imagem da feiticeira a ela imposta, incutida no imaginário coletivo dos habitantes da aldeia, se mostra tanto sexista quanto racista, proporcionando, a suas(seus) opressoras(es), um duplo exercício de poder. $^{24}$

\footnotetext{
23 A figura de Tituba como "mãe preta" de crianças de Salem se destaca como primeira cena do filme As bruxas de Salem, lançado em 1996, sob a direção de Nicholas Hynter, na qual Tituba entretinha as crianças e, a partir da qual, posteriormente, é acusada do crime de feitiçaria. Ainda que Tituba esteja ao centro da primeira cena, a trama do filme está centrada na relação, religiosa e socialmente interdita, entre a jovem Abigail Williams (interpretada por Winona Ryder; e que, presente na cena inicial, lidera o grupo de meninas que denuncia Tituba ao tribunal) e John Proctor (interpretado por Daniel Day-Lewis, um fazendeiro casado, que se envolveu com Abigail quando esta trabalhou para ele).

24 A dupla atribuição de gênero à opressão, na forma do qualificativo suas(seus), faz jus a um esforço interseccional, geralmente bastante difícil de se levar a termo nas análises literárias propriamente ditas, a despeito de compor a base mesma de um princípio interseccional de análise, a saber, a possibilidade de que mulheres não racializadas imputem violências a mulheres racializadas - possibilidade essa proporcional à eventual universalidade atribuída a uma definição da categoria "mulher" (e, por conseguinte, das teorias e metodologias feministas em jogo), no interior das análises literárias. Em um cenário hipotético, ante a análise literária da diegese do romance de Condé, quiçá se apresentassem dificuldades a análises não interseccionais quando da compreensão da relação entre Susanna Endicott e Tituba, no sentido de uma resistência - de parte da análise literária - a compreender opressões imputadas a mulheres por outras mulheres que, a despeito da categoria ou variável gênero, podem apresentar outras variáveis necessárias ao cálculo de compreensão e agência sobre tais opressões.
} 
À guisa de conclusão, como trabalho científico que visa a compreender o lugar da mulher negra colonizada, na diegese do romance, foi possível investigar, desde as experiências próprias e situadas de Tituba, como práticas excludentes e reducionistas impostas pelo sistema moderno-colonial de gênero atuam em sua condição social, deslocando-a às camadas mais inferiores das hierarquias dicotômicas, reduzindo-a ao não humano, à promiscuidade, à objetificação do corpo como natureza, justificativas a sua escravização. ${ }^{25}$ Tais imagens constituem o que Lugones denomina lado oculto/escuro do sistema de gênero, onde estariam situadas(os), conforme esse marco teórico, sujeitas(os) em-intersecção, como, por exemplo, mulheres negras, mulheres indígenas e sujeitas(os) do terceiro gênero. $\mathrm{O}$ seu oposto, o lado claro/visível, caracterizado pelo dimorfismo biológico, pela organização patriarcal e pela heteronormatividade, normatizou e condenou homens e mulheres colonizadas visto que nesse polo sujeitas(os) no polo oposto não eram consideradas(os) humanas(os), por não pertencer, não se circunscrever a uma ideia de humanidade homóloga ao fenótipo branco, não racializado. Nesse sentido, os personagens Samuel Parris e Elizabeth Parris, na diegese do romance de Condé, apresentam a ideia de homem e de mulher no sentido hegemônico do termo, na qual o primeiro representa o sujeito heterossexual, cristão e civilizado, ao passo que a segunda é subordinada ao homem branco e reduzida à reprodutora da raça e do capital. Também, interpretamos o episódio da caça às bruxas como possível consequência da colonização e da colonialidade do gênero, hipótese que permitiu estabelecer as bases para um esforço de análise interseccional

\footnotetext{
25 A desumanização de sujeitas(os) negras(os), como base para a justificativa de sua escravização, haja vista sua recorrência em distintas literaturas nacionais (GLISSANT, 1997), poderia, por si só, oferecer um tópos para abordagens literárias de cunho comparativo entre ficcionalidades amefricanas nas Américas.
} 
com vistas a compreender a posição de Tituba no processo misógino e feminicida ocorrido em Salem, dado que sua condenação é justificada não apenas pelo gênero mas, também, pela raça, configurando uma imagem interseccional (racista e sexista) da bruxa não branca.

\section{Referências}

ALVES, Alcione. Notas introdutórias sobre a noção de ancestrais em Yolanda Arroyo Pizarro. In: MENDES, Algemira de Macêdo; LOPES, Sebastião Alves Teixeira. (org.). Teias e tramas: literaturas e discursos de gênero. Teresina: Edufpi, 2015. p. 14-31.

ANZALDÚA, Gloria. Falando em línguas: uma carta para as mulheres escritoras do terceiro mundo. Revista Estudos Feministas, Florianópolis, v. 8, n. 1, p. 229-236, 1. sem. 2000. BAIRROS, Luiza. Nossos feminismos revisitados. Revista Estudos Feministas, Florianópolis, v. 3, n. 2, p. 458-463, 2. sem. 1995.

BERNADINHO-COSTA, Joaze; GROSFOGUEL, Rámon. Decolonialidade e perspectiva negra. Revista Sociedade e Estado, Brasília, v. 31, n. 1, p. 15-24, jan./abr. 2016.

CARDOSO, Claudia Pons. Outras falas: feminismos na perspectiva de mulheres negras brasileiras. 2012. $383 \mathrm{f}$. Tese (Doutorado em Estudos Interdisciplinares sobre Mulheres, Gêneros e Feminismo) - Faculdade de Filosofia e Ciências Humanas, Universidade Federal da Bahia, Salvador, 2012.

CARNEIRO, Sueli. Enegrecer o feminismo: a situação da mulher negra na América latina a partir de uma perspectiva de gênero. Geledés Instituto da Mulher Negra, São Paulo, 06 mar. 2011. Disponível em: http://www.geledes.org.br/suelicarneiro-enegrecer-o-feminismo-a-situacao-da-mulher-negrana-america-latina-a-partir-de-uma-perspectiva-de-genero. 
Acesso em: 26 fev. 2021.

CARNEIRO, Sueli. A construção do outro como não ser como fundamento do ser. Tese (doutorado em Educação). São Paulo: Universidade de São Paulo, 2005, p. 96-110.

COLLINS, P. H. Rasgos distintivos del pensamento feminista negro. In: JARBADO, Mercedes (org.). Feminismos negros: una antologia. Tradução de Mijo Miquel et al. Madrid: Traficantes de Sueños, 2012. p. 99-134.

CONDÉ, Maryse. Eu, Tituba: bruxa negra de Salem. Tradução de Natalia Borges Polesso. Rio de Janeiro: Rosa dos Tempos, 2019.

DUSSEL, Henrique. Europa, modernidade e eurocentrismo. In: LANDER, Edgardo (org.). A colonialidade do saber: eurocentrismo e ciências sociais. Perspectivas latinoamericanas. Buenos Aires: CLACSO, set. 2005. Disponível em: http:// www.antropologias.org/rpc/files/downloads/2010/08/ Edgardo-Lander-org-A-Colonialidade-do-Saber-eurocentrismoe-ci\%C3\%AAncias-sociais-perspectivas-latinoamericanasLIVRO.pdf. Acesso em: 18 jan. 2021.

ESPINOSA MIÑOSO, Yuderkys. Una crítica descolonial a la epistemología feminista crítica. El cotidiano, México, n. 184, p. 7-12, mar/abr. 2014.

GAZTAMBIDE-GEIGEL, Antonio. La invención del Caribe en el siglo XX. Las definiciones del Caribe como problema histórico y metodológico. Revista Mexicana del Caribe, v. 3, n. 7, 1996, p. 74-96.

GENETTE, GERARD. Discurso da narrativa. Tradução de Fernando Cabral Martins. Lisboa: Veja, 1971.

GLISSANT, Édouard. Le discours antillais. Paris: Gallimard, 1997.

GLISSANT, É. O Mesmo e o Diverso; Técnicas. Tradução de Normelia Parise. Antologia de textos fundadores do comparatismo literário interamericano. Comentário de Graciela Ortiz. Disponível em: https://www.ufrgs.br/cdrom/ 
glissant/index.htm.

GONZÁLEZ, Lélia. A categoria político-cultural da Amefricanidade. In: GONZÁLEZ, Lélia. Primavera para as rosas negras: Lélia González em primeira pessoa. Diáspora Africana: Editora Filhos da África, 2018, p. 321-334.

GROSFOGUEL, Rámon. Para descolonizar os estudos de economia política e os estudos pós-coloniais: Transmodernidade, pensamento de fronteira e colonialidade global. Revista crítica de ciências sociais, n. 80, p. 115-147, mar. 2008.

HOOKS, Bell. Mujeres negras: dar forma a la teoría feminista. In: HOOKS, bell et al. Otras inapropriables. Feminismos desde las fronteras. Traducción de Maria Serrano Gimenez et al. Madrid: Traficantes de sueños, 2004.

HOOKS, Bell. Não sou eu uma mulher: mulheres negras e feminismo. Lisboa: Plataforma Gueto, 2014.

LUGONES, María. Colonialidad y género. Tabula Rasa, Bogotá, n. 9, p. 73-101, jul/dic. 2008. Disponível em: http:// www.revistatabularasa.org/numero-9/05lugones.pdf. Acesso em: 2 mar. 2021.

LUGONES, María. Multiculturalismo radical y feminismos de mujeres de color. Revista Internacional de Filosofía Política, México, n. 25, p. 61-76, 2005. Disponível em: http://www. redalyc.org/pdf/592/59202503.pdf. Acesso em: 02 mar. 2021.

LUGONES, María. Rumo a um feminismo descolonial. Revista Estudos feministas, Florianópolis, v. 22, n. 3, p. 935-952, set/ dez. 2014.

MALDONADO-TORRES, Nelson. Sobre la colonialidad del ser: contribuciones al desarrollo de un concepto. In: CASTROGÓMEZ, Santiago.; GROSFOGUEL, Ramón. (org.). El giro decolonial: reflexiones para una diversidad epistémica más allá del capitalismo global. Bogotá: Iesco Pensar-Siglo del Hombre Editores, 2007.

MBEMBE, Achille. Necropolítica. São Paulo: N-1 Edições, 2018. 
MENDOZA, Breny. La epistemología del sur, la colonialidad del género y el feminismo latino-americano. In: MIÑOSO, Yuderkys Espinosa; CORREAL, Diana Gómez; MUÑOZ, Karina Ochoa (org.). Tejiendo de otro modo: Feminismo, epistemología y apuestas descoloniales en Abya Yala. Popayán: Editorial Universidad del Cauca, 2014.

MIGNOLO, Walter D. Histórias locais/projetos globais: Colonialidade, saberes subalternos e pensamento liminar. Tradução de Solange Ribeiro de Oliveira. Belo Horizonte: Editora UFMG, 2020.

MILAGROS, Martínez Reinosa; GARCÍA, Félix Valdés. ¿De qué Caribe hablamos? In: SALAZAR, Luis Suárez; AMÉZQUITA, Gloria. El gran Caribe en el siglo XXI: crisis y respuestas. Ciudad Autónoma de Buenos Aires: CLACSO, 2013, p. 21-33. Disponível em: http://biblioteca.clacso.edu.ar/ clacso/gt/20130628121000/ElGranCaribe.pdf. Acesso em: 23 dez. 2021.

NAVARRETE, Julio Mejía. Colonialidad y des/colonialidad en América Latina: elementos teóricos. Geografhia, v. 15, n. 30, p. 8-32, 2014.

NAVARRO, Romulo F. A evolução dos materiais. Parte II: a contribuição das civilizações pré-colombianas. Revista Eletrônica de Materiais e Processos, v. 3.1, p. 15-25, 2008.

OLIVEIRA, Jônata Alisson Ribeiro de. A resistência ao olho do poder: rastro, gênero e colonialidade no romance $\mathrm{Eu}$, Tituba, feiticeira... negra de Salem, de Maryse Condé. 82f. Dissertação (Mestrado em Letras). Universidade Federal do Piauí. Teresina, 2016. Disponível em: https://repositorio.ufpi.br/xmlui/ handle/123456789/1164. Acesso em: 23 dez. 2021.

QUIJANO, Aníbal. Colonialidad y Modernidad/racionalidade. Perú Indígena, v.13, n. 29, p. 11-20, 1992. Disponível em: https://pt.scribd.com/doc/70586547/Quijano-Colonialidad-yModernidad-1992. Acesso em 18 jan. 2021.

QUIJANO, Aníbal. Colonialidade do poder, eurocentrismo e América Latina. In: LANDER, Edgardo (org.). A colonialidade 
do saber: eurocentrismo e ciências sociais. Perspectivas latinoamericanas. Buenos Aires: CLACSO, set. 2005. Disponível em: http://www.antropologias.org/rpc/files/downloads/2010/08/ Edgardo-Lander-org-A-Colonialidade-do-Saber-eurocentrismoe-ci $\%$ C $3 \%$ AAncias-sociais-perspectivas-latinoamericanasLIVRO.pdf. Acesso em: 18 jan. 2021.

SANTOS, Vívian Matias dos. Notas desobedientes: decolonialidade e a contribuição para a crítica feminista à ciência. Psicologia \& Sociedade, Belo Horizonte, v. 30, p. 1-11, 2018.

SANTOS, Boaventura de Sousa. Para além do Pensamento Abissal: das linhas globais a uma ecologia de saberes. Revista Crítica de Ciências Sociais, n. 78, p. 3-46, 2007.

SCOTT, Joan. A história das mulheres. In: BURKE, Peter (org.). A escrita da história: novas perspectivas. Tradução de Magda Lopes. São Paulo: Editora da Universidade Estadual Paulista, 1992.

TRUTH, Sojourner. E eu não sou uma mulher? Porto Alegre: Figura de Linguagem, 2019.

WERNECK, Jurema. Nossos passos vêm de longe! Movimentos de mulheres negras e estratégias políticas contra o sexismo e o racismo. Revista da ABPN, v. 1, n. 1, p. 1-11, mar/jun. 2010. Disponível em: http://www.abpn.org.br/Revista/index.php/ edicoes/article/viewFile/20/22. Acesso em: 11 mar. 2021.

WYNTER, Sylvia. 1492: una nueva visión del mundo. In: GARCÍA, Felix Valdés (org.). Antología del pensamiento crítico caribeño contemporâneo. Ciudad Autónoma de Buenos Aires: CLACSO, 2017, p. 367-430. Disponível em: http://biblioteca.clacso.edu.ar/clacso/se/20170707025855/ AntologiaDePensamientoCriticoCaribeno.pdf. Acesso em: 29 set. 2021. 